\title{
Marching for 3D Printing: Its Potential to Promoting Access to Healthcare in Africa
}

\author{
Solomon Tekle Abegaz \\ Additional information is available at the end of the chapter \\ http://dx.doi.org/10.5772/intechopen.75649
}

\begin{abstract}
Technology has the capacity for helping African citizens realize their basic rights. The recent introduction of the disruptive technology-3D printing-has the potential to impact millions of lives through a variety of revolutionary medical solutions, including surgery and the treatment of intractable health conditions. As the technology progresses, so does the practical enjoyment of health rights. This chapter argues that the human rights-based approach to 3D printing technology can be helpful in focusing discussions and actions on health well-being and security for individuals in Africa. Having first analyzed the impact of the technology in revolutionizing healthcare, the chapter provides an overview of the complex health challenges this young continent is faced with. Further, it also explores the most relevant African regional laws and standards, guidelines and policy initiatives requiring African governments to use technologies that can advance the human right to health. It concludes that the healthcare agenda of African countries needs to be better integrated and coordinated to ensure that the technologies have a positive impact on health rights. It further concludes that the African Union Commission should promote the researching and utilization of this technology in the implementation of national health policies and strategies of African countries.
\end{abstract}

Keywords: 3D printing, access to healthcare, Africa, human rights, technology

\section{Introduction}

Relatively new in its adoption, 3D printing technology is a rapidly expanding method of manufacturing that has found numerous applications in areas such as automotive, aerospace and defense industries [19]. 3D or three-dimensional object printing is an additive manufacturing process that creates a physical object from a digital design. It is a set of processes in 
which material is joined or solidified under computer control to create a three-dimensional object, with material being added together. 3D Printing is used in both rapid prototyping and additive manufacturing [13]. In the realm of health, the introduction of the disruptive technology -3D printing - has the potential to impact on millions of lives through a variety of revolutionary medical solutions including surgery and the treatment of otherwise difficult health conditions. The application of technology in the area of health is wide ranging. 3D printing can help generate a part of the human body that is an accurate replicate of a patient's own structure. Experts have developed 3D printed skin for burn victims and airway splints for babies. Also, 3D printed models made of different materials representing bone, organs and soft tissue are produced in a single print procedure. 3D printers are also playing significant roles in improving the success rates of stages, but first tests are looking promising in a variety of areas, operations and for crafting amazing artifacts. Many 3D printed medical solutions are still in their experimental stage.

Despite the revolution being brought about by technology in the medical sector together with some developments seen on the continent concerning the application of technology in general $[13,14,15]$, access to healthcare remains a huge challenge in Africa. The continent is confronted with an increased demand beyond the treatment of AIDS, malaria and other communicable diseases to address the non-communicable ones such as heart attacks and cancers. There are a variety of illnesses throughout the continent-half the population still lacks adequate health services. According to researches, fewer than $50 \%$ of Africans have access to modern health facilities [16]. Further, many African countries spend less than $10 \%$ of their Gross Domestic Product (GDP) on healthcare. This is in contradiction with African governments' political commitment they made to allocating $15 \%$ of their GDP to the health sector pursuant to the Abuja Declaration of 2001. Only very few African countries have implemented this objective [17]. Africa is faced with a dearth of trained healthcare professionals as many of them prefer to live and work in places like the USA and Europe.

In order to address the challenges of access to healthcare to their needy populations, African States have assumed several obligations under regional human rights treaties and non-binding political commitments. These norms and standards obligate States Parties to those treaties and declarations, inter alia, to fulfill the right of access to healthcare-a duty is placed on States to actively implement the right. There are several ways in which access to healthcare will be enjoyed, such as through adoption of cost-effective technologies. As the technology progresses, so does the practical enjoyment of health rights. African countries have to embrace technology to close the healthcare gap, thereby performing their heath rights' obligation to their people in accordance with agreed regional human right norms and standards.

Due to the relatively new introduction of the 3D printing, the link between this technology, the human right to healthcare and the obligation of States has not been fully explored. This chapter therefore seeks to critically examine whether the human rights-based approach to 3D printing can be helpful in focusing discussions and actions on health well-being and security of individuals in Africa. The chapter is structured into six sections. Preceded by a brief introduction about 3D printing, health and human rights obligations to healthcare in general in section one, section two describes the 3D technology and its application with a focus on its 
medical application, section three assesses the situation of access to healthcare as a challenge in Africa and the African countries' obligation to create conditions which would assure to all medical services and medical attention in the event of sickness of their needy population. Capitalizing on the State obligation to make healthcare available and accessible, section four and five are allocated for the discussion on the essentials of utilizing the benefits of 3D technology as a human right to address access to healthcare gaps in Africa. Finally, the chapter closes by concluding the entire discussion.

To do this research, the writer reviewed the scholarly literature, reports, technology-focused websites, human rights law and relevant organizational statements. The chapter relies heavily on elaborations given by relevant United Nations (UN) treaty bodies to identify substantive rights of access to healthcare and the obligation they entail against African governments that signed relevant human rights treaties. The sources for institutional statements are the primary websites of UN agencies and treaty bodies, major government bi-lateral organizations and international Non-Governmental Organizations (NGOs) working actively in health. The overall objective is to promote the capitalization of the technology by informing the African governments and people of Africa, disseminating information, educating people and popularizing the subject so people can claivm the benefit of the technology. It is hoped that the work will eventually lead to leveraging 3D printing as a driving force in Africa's health rights' safeguards.

\section{Evolution of 3D technology and its utilization in the healthcare}

Undoubtedly, technology can be utilized to disrupt or promote human security. Technology can facilitate repression through censorship of expression, block or filter access to information, monitor online activity and more effectively and efficiently control populations than in the pre-digital world [35]. Equally, it can also be innovatively, creatively and very effectively used to sensitize communities regarding issues that require advocacy, promotion and protection, such as health rights [18].

An example of innovative technology that recently emerged with many benefits for human security is 3D printing. The modern history of 3D printing dates back to the 1980s when Charles Hull invented the stereo-lithography apparatus (SLA) Printer around 1987 [24]. Since then, there is an ever-growing list of astounding accomplishments using 3D printing. In 2004 and 2005, a Chinese company WinSun developed a 3D printing spray nozzle and automatic material feeding systems. Three years later, in 2008, they printed an actual wall for a building [27]. In 2015 WinSun printed a five-storey residential apartment building [27]. But they did not stop there. To top off this feat, they also built a 3D printed 1100 square meter villa that came complete with internal and external decorations. Today, the technology is expanding rapidly; almost every week new printers and printing materials offering novel possibilities as well as excfiting new applications appear [19]. In the case of Dubai-based construction firm Cazza Technologies, the company's large robotic 3D printers already allow them to construct architecturally complex buildings at unprecedented speeds. All of the essential structural 
components for tall buildings, including reinforcements with steer rebar, can be 3D printed using this technology [20]. The leading countries in the world immersed with this technology are the USA followed by the United Kingdom and New Zealand.

Coming to the medical application of the technology, this is rapidly creating new ways by which the medical industry can enhance our lives and save billions of dollars in healthcare costs. As highlighted in the introductory section, the additive manufacturing applications within the medical community are diverse. It is recognized that medical uses for 3D printing, both actual and potential, will bring revolutionary changes [21]. They can be organized into several broad categories including: creation of customized prosthetics, implants and anatomical models, tissue and organ fabrication, manufacturing of specialty surgical instruments, pharmaceutical research regarding drug fabrication, dosage forms, delivery and discovery as well as manufacturing medical devices [24]. Concerning implantation, researchers are now using 3D printers to cheaply create medical devices that can be directly implanted into the human body. Doctors have fashioned 3D-printed splints to help children with rare breathing disorders and have successfully implanted a 3D-printed titanium sternum and ribs into a cancer patient [23]. Benefits provided by application of 3D printing in medicine include not only the customization and personalization of medical products, drugs and equipment but also cost-effectiveness, increased productivity, the democratization of design and manufacturing and enhanced collaboration. The technology enables quick, cost-effective development of new medical devices as well as customized end-use products that improve the delivery and results of a patient's care [26].

In terms of its cost, except in recent years, the average cost of a 3D printer was floating around the $\$ 50 \mathrm{k}$ mark, but due to consumerism and an increase in demand and subsequently production, one can now purchase a respectable 3D printer for the substantially lower cost of $\$ 1800$ [27]. If that is still too expensive for our pockets, there is even a $\$ 49$ 3D printer available for pre-order on Kick starter [27]. Despite the seeming affordability of the technology in some areas, it is the majority of the Western world that embraces the benefits of advanced technology, with Sub-Saharan Africa still working to provide for the most basic needs such as adequate healthcare, food and sanitation. Healthcare development without an eye toward improving technological capacities is likely to further hamper Sub-Saharan Africa's overall well-being [1].

Whereas 3D technology is not an end in itself, its effective usage empowers people and communities to become self-sufficient in meeting their basic needs and reach their full potential. The 3D technology has several connected advantages for the continent Africa, ranging from the provision of an impetus to the democratization process and good governance; facilitating Africa's integration into the new information society by use of its cultural diversity as a leverage; helpful tools for a wide range of applications such as remote sensing and environmental, agricultural and infra-structural planning. While technology in general and 3D printing in particular offers several of these possibilities to promote healthcare and the overall the development of the African region, there is limited influence of technology in healthcare. The deprivation of technology in general prevents individuals in certain parts of the world, for instance in the countries making up Sub-Saharan Africa, from realizing certain fundamental, internationally recognized rights, such as the right to health [1]. Partly for this 
reason, patients in Sub-Saharan Africa, thus have very limited or no access to healthcare clinics and basic health. The section that follows gives an overview of some of the challenges of healthcare service in the region.

\section{Challenges to healthcare in Africa: An overview}

Not all things in Africa are going bad, despite that it is considered as a backward or dark continent. There are initiatives in the health sector that are moving in the right way. A large number of African countries, such as Senegal, Ghana, Gabon, Cote d'Ivoire, Kenya and Benin, have begun to work at setting up various types of universal medical insurance coverage in an effort to reduce social inequalities. In addition, international solidarity (Global fund, Gates Foundation, etc.) and pressures from civil society have made possible a number of successes against diseases such as onchocerciasis (river blindness), polio, human immune-deficiency virus and tuberculosis. Here, mention must be made of the 300 or so medical doctors trained at the School of Medicine in Dakar (Senegal) by French professionals between 1918 and 1950, who made a major contribution to the almost complete eradication of the epidemic and endemic diseases that took a heavy toll on West African peoples, such as trypanosomiasis (sleeping sickness), plague, yellow fever and smallpox [30]. As a result, Africa's healthcare coverage to the rural population has grown exponentially.

Despite the efforts made in improving the healthcare systems by African countries, enormous challenges exist within this sector. Unfortunately, preventable deaths of children under five remain very high in Sub-Saharan Africa due to poor access to timely and quality healthcare interventions [28]. While child mortality rates have plummeted since the 1990s, evidence shows that progress on its reduction in most developing countries has witnessed a widening gap as well as a concentration of 'under-five' deaths in the most deprived communities [28]. Eighty-three per cent of the highest number of people in rural areas who are not covered by essential healthcare services is in Africa. However, it is not only rural Africa that the center of access to healthcare is a challenge. It seems even those who lead Africa are not in a different position. It is not uncommon to see many African leaders and government officials traveling to get their medical treatment abroad. Ian Taylor has observed that from 2000 to 2012, 10 African heads of states who have died from natural causes had been receiving medical care abroad and except 2, the rest have died abroad while receiving treatment [29]. This demonstrates that African leaders lack confidence in their own country's healthcare systems. A failure to invest in national healthcare systems in Africa, which ultimately will lead to extreme shortages of healthcare facilities, goods and professional personnel, is the potential cause of the problem.

Another unfortunate fact in Africa is it bears one-quarter of the global disease burden, yet has only $2 \%$ of the world's doctors. While medical professionals in neuron-related diseases are in demand, whether in the area of neurosurgeons, or neurologists, or neuroradiologists, there is not a single facility in all of sub-Saharan Africa (except South Africa) dedicated to diseases of the nervous system on the level of the criteria followed in the countries of the northern hemisphere [30]. Unfortunately, the ratio of neurosurgeon/capita in sub-Saharan 
is $1 / 3,000,000$ while it is $1: 200,000$ in the northern hemisphere. On the other hand, in medical imaging, sub-Saharan Africa's ration is $1 \mathrm{MRI} / 25$ million inhabitants, while it is $25 \mathrm{MRIs} /$ one million inhabitants in the northern hemisphere [30]. Life expectancy in Africa is 15 years lower than the global average because the continent has to deal with the significant burden of epidemics without the infrastructure to fight them. The continent is, according to the Gates Foundation, a mix of new and persistent healthcare challenges [30].

Researchers predict that non-communicable diseases such as diabetes, cancer and cardiovascular disease will overtake communicable and nutritional diseases by 2030. Right now communicable diseases such as malaria, pneumonia, Ebola, HIV/AIDS and even leprosy have a negative effect on continental growth [30]. It was in view of addressing the physical and mental challenges that disease or ill-health might bring about to humans that human rights laws promised the right of everyone to the highest attainable standard of physical and mental health, which includes access to all medical services.

\section{Access to healthcare as a human right in Africa}

The African continent is faced with a myriad of human rights challenges - "surveillance, privacy laws, threats, imprisonment, intimidation and killings have been happening across the continent, lending to the assertion that regional institutions with a human rights mandate are largely failing to protect the victims" [18]. However, human rights interests in Africa are not limited to the protection from unlawful detention, freedom from censorship of opinion and arbitrary killings. Equally, human rights are also about the ability to enjoy a variety of facilities, goods, services and conditions necessary for the realization of the highest attainable standard of health [3]. True, ensuring a healthy life is the spindle upon which a person's whole personality and well-being depend. To be without healthcare is a frightening prospect, for death is the inevitable consequence [29]. Access to healthcare helps people identify and seize opportunities to grow and develop and to better their lives and those of their families and communities. It also facilitates an individual's participation in society, in the economy, in government and in the development process itself.

Human rights lay standards, norms and principles - they aim to ensure human well-being. Focusing on the right to health, it is one of the fundamental human rights enshrined in the leading and binding human rights documents, including the Constitution of World Health Organization (WHO), 1946, where health is defined as "a state of complete physical, mental and social wellbeing and not merely the absence of disease or infirmity" [2]. The preamble further states that "the enjoyment of the highest attainable standard of health is one of the fundamental rights of every human being without distinction of race, religion, political belief, economic or social condition." The 1948 Universal Declaration of Human Rights also mentioned health as part of the right to an adequate standard of living [8]. Again, the 1966 International Covenant on Economic, Social and Cultural Rights (ICESCR) [5]; the 1969 International Convention on the Elimination of All Forms of Racial Discrimination (ICERD) [34]; the 1975 Convention on the Elimination of All Forms of Discrimination Against Women 
(CEDAW) [32]; the 1989 Convention on the Rights of the Child (CRC) [11] and the Convention on the Rights of Persons with Disabilities [33] stipulate that the right to health is to be enjoyed by everyone without discrimination. Moreover, States have committed themselves to protecting this right through international declarations, domestic legislation [12] and policies and at international conferences. In this way, the right in question has also been proclaimed by resolution 1989/11 of the Commission on Human Rights, the Vienna Declaration and Program of Action of 1993, the Millennium Development Goals (MDGs) and the Sustainable Development Goals (SDGs).

Parallel to global human rights treaties, regional human rights conventions, including the 1996 European Social Charter (as revised) [31], the 1999 Additional Protocol to the American Convention on Human Rights in the Area of Economic, Social And Cultural Rights [7], the 1981 African Charter on Human and People's Rights (also known as the "Banjul Charter") [10], as well as the African Charter on the Rights and Welfare of the Child [9] uphold that the right to access to healthcare is a fundamental human right that needs to be respected, promoted and fulfilled. Every State has ratified at least one international human rights treaty recognizing the right to health. Thus, they have the obligation to respect, protect and fulfill the right to healthcare to their needy populations.

The incorporation of health as a human right in the various global and regional treaties implies that everyone has the right to the highest attainable standard of physical and mental health, which includes access to all medical services. Again, the human right to healthcare means that hospitals, clinics, medicines and doctors' services must be accessible, available, acceptable and of good quality for everyone on an equitable basis, where and when needed [3]. Except those obligations that have immediate effect, (i.e., States' immediate obligation in relation to the right to health are that they have to guarantee that the right will be exercised without discrimination of any kind and the obligation to take steps toward the full realization of the right) [3], States have the obligation to progressively realize the right to health over a period of time. Meaning that, States' parties that have ratified a treaty which incorporates the right to health have a specific and continuing obligation to move as expeditiously and effectively as possible toward the full realization of the right. The realization of their obligation may be pursued through numerous, complementary approaches, such as the formulation of health policies or the implementation of health programs, or the adoption of specific legal instruments [3]. This chapter focuses and suggests the African States' obligation to adopt programs aimed at ensuring their healthcare-needy population enjoys the benefits of the 3D technology and its application for the realization of the right.

\section{The obligation to benefit $3 \mathrm{D}$ technology in realizing access to healthcare}

The link between the right to enjoy the benefits of scientific progress and other human rights, notably the right to health, has been underscored. Scientific and technological advancement are crucial in health development and poverty reduction. According to Yvonne Donders, the 
right of individuals to enjoy the benefits of scientific advancement implies the right of access to scientific and technological advancement. In this regard, the African States adoption of the Universal Declaration of Human Rights (UDHR) and ICESCR that guarantee the right to enjoy the benefits of scientific progress and its applications is a step in the right direction $[5,8]$. The African States' obligation to healthcare moves further to ratifying global and regional treaties. Equally, they have the responsibility for incorporating into their domestic legal and policy framework an individual's right to enjoy the benefits of the 3D technology (which is a result of advancement or practical application of science) progress and its applications in the area of health. This emanates not only because the enjoyment of benefits of science and its application is a fundamental right, but also the realization of the right to healthcare imposed an obligation on the part of the States to make administrative, financial, educational, social and other measures, including judicial remedies [4].

In implementing the right to enjoy the benefits of scientific progress and thereby to foster healthcare services, States are under an obligation to invest, to the maximum possible, in scientific and technological advancement and share the benefits. Against this background, the development of vaccines and medicines against widespread diseases has done much to improve life expectancy. In the same way, science and research in the field of information technology, including mobile telephones, the internet and satellite television, have accelerated the flow of information throughout the world, which has proven particularly beneficial to developing countries. It is thus submitted that African States have the obligation to invest, to the maximum possibility, in 3D technological advancement and share the benefits to promote access to healthcare services. International co-operation and solidarity are equally crucial in this regard for African countries to discharge their obligation. This is especially important for ensuring availability of resources from the international community when resources are scarce within African States.

\subsection{Africa Union Commission: Its mandate to promote healthcare in Africa}

The African Charter on Human and Peoples' Rights is the foremost African legal instrument intended to protect and promote human rights and basic freedoms on the continent. As noted previously, the right to healthcare is protected under article 16 of this instrument. In addition, the Charter also crafts mechanisms of promoting the spectrum of rights enshrined there. The African Commission on Human and Peoples' Rights (hereinafter "the African Commission or the Commission") is a mechanism designed to promote human rights [10], including the right of access to healthcare in the region. The Commission is composed of 11 members chosen from among African personalities of the highest reputation, known for their high morality, integrity, impartiality and competence in matters of human and peoples' rights. In particular, the Commission's promotional mandate includes [10]:

To collect documents, undertake studies and research on African problems in the field of human and peoples' rights, organize seminars, symposia and conferences, disseminate information, encourage national and local institutions concerned with human and peoples' rights, and, should the case arise, give its views or make recommendations to governments;.... 
Using the foregoing mandate, the Commission has made several efforts to promote the realization of the right to healthcare on the continent. For instance, the Commission adopted Resolution 141 (Access to Health and Needed Medicines in Africa) following advocacy by the Human Rights and Access to Medicines Clinical Group, a collaboration of the Centre for Human Rights at the University of Pretoria and the Washington College of Law at American University. In its resolution the Commission states that "access to needed medicines is a fundamental component of the right to health and that States Parties to the African Charter have an obligation to provide where appropriate needed medicines, or facilitate access to them" [6].

In the same vein, the Commission can use a wide range of promotional activities, including dissemination of information, making recommendations on the gaps in access to healthcare on the continent and the need to critically study and design strategies for the application of $3 \mathrm{D}$ technology for the progressive realization of the right through available resources.

\section{Conclusion}

Increasingly, African governments express their commitment to the defense of human and peoples' rights of access to healthcare on the continent by issuing various norms and standards as well as setting up various institutions relating to human rights protection and promotion on the continent. Among the various norms included are article 16 of the African Charter on Human and Peoples' Rights, article 14 of the African Charter on Human and Peoples' Rights, Protocol to the African Charter on Human and Peoples' Rights on the Rights of Women in Africa, article 14 of the African Charter on the Rights and Welfare of the Child, as well as article 16 the African Youth Charter.

Regrettably, in spite of these lofty ideas, the daily lives of Africans do not always manifest the concrete benefits of these initiatives. Africa remains beset, as it were, by gaps in implementing healthcare rights caused by factors such as socio-economic and political problems, corruption, poverty, armed conflicts and the abuse of individuals' fundamental rights. More remains to be done in order to translate the benefits of human rights protection and promotion into the daily healthy lives of the peoples of Africa. To address the challenges, African States must focus on building better healthcare infrastructures. Africa's existing promotional activities need to be catapulted by amalgamating 3D technology in implementation. This needs to happen in a flawless manner.

To better adopt the technology, the African Commission should urge African States to guarantee the full scope of access needed to 3D technical applications in medicine. There is a need for developing a communication strategy aimed at strengthening the Commission's corporate identity and the positioning of its activities in the area of advancing medical care. Such a strategy should build and maintain creative and effective communication partnerships, particularly with the technologically developed world; promote 3D technology usage; ensure responsiveness to the rapidly changing $3 \mathrm{D}$ technology and environments and advocate for media 
liberalization and deregulation to ensure a more central, dynamic and effective contribution of communication to the work of the Commission. Driven by technological convergence, it is here argued that the concentrated use of 3D technology can bring unprecedented comparative advantages to the continent. The knowledge-based economy of the future will depend more and more on the effective use of this technology. Rapid advances in technology coupled with the low-cost of acquiring 3D technology tools are opening new windows of opportunity for Africa to accelerate access to healthcare services. The 3D printing revolution can accelerate Africa's goals in the right to health, fostering intra-regional trade, integration into the global economy, as well as realizing its security needs. This must be reinforced by African governments' political will to improving knowledge, skills and resources and creating collaboration and consensus among key stakeholders.

\section{Acknowledgements}

My first impression to ponder upon the link between 3D technology and its medical application happened in a collaboration research discussion conducted with colleagues at the University of Gondar in Ethiopia in early 2017. Hence, my thanks goes to the University of Gondar for providing a platform for the meeting of experts in the field of law, technology and human rights. My special thanks goes to my friend and colleague, Dr. Hailemichael Demissie, who first tabled the importance of 3D printing technology for harnessing Africa's development, on the basis of which I personally appreciated the significance of linking 3D printing as a useful avenue for promoting the right to healthcare in Africa.

\section{Author details}

Solomon Tekle Abegaz

Address all correspondence to: solomomte@gmail.com

School of Law, University of Gondar, Gondar, Ethiopia

\section{References}

[1] Jennifer MM. Human rights and development: Using advanced technology to promote human rights in sub-Saharan Africa. Case Western Reserve Journal of International Law. 1998;30(343):343-371

[2] World Health Organization (WHO). Constitution of the WHO. 1946

[3] UN Committee on Economic, Social and Cultural Rights. General comment no. 14. The Right to the Highest Attainable Standard of Health. Article 12 of the Covenant. 11 August 2000. E/C.12/2000/4 
[4] UN Committee on Economic, Social and Cultural Rights. General comment no. 3. The Nature of States Parties' Obligations. Article 2 of the Covenant. 14 December 1990. $\mathrm{E} / 1991 / 23$

[5] UN General Assembly, International Covenant On Economic, Social and Cultural Rights. December 16, 1966. United Nations, Treaty Series, 993

[6] The African Commission on Human and Peoples' Rights. Resolution on Access to Health and Needed Medicines in Africa. November 24, 2008

[7] Organization of American States (OAS). Additional Protocol to the American Convention on Human Rights in the Area of Economic, Social and Cultural Rights. November 16, 1999. A-52

[8] UN General Assembly, Universal Declaration of Human Rights. December 10, 1948. 217 A III

[9] Organization of African Unity (OAU). African Charter on the Rights and Welfare of the Child. 1999

[10] OAU. African Charter on Human and Peoples' Rights ("Banjul Charter"). June 27, 1981. CAB/LEG/67/3 rev. 5, 21 I.L.M. 581982

[11] UN General Assembly Convention on the Rights of the Child. November 20, 1989. United Nations, Treaty Series, 1577

[12] Constitution of the Republic of South Africa. 1996

[13] Christopher B. 3D printing: Third edition. CreateSpace Independent Publishing Platform; 2016. pp. 1-318

[14] 3D Hubs. What is 3D printing?: The definitive guide to additive manufacturing [Internet]. Available from: https://www.3dhubs.com/what-is-3d-printing [Accessed December 25, 2017]

[15] Wikipedia. 3D printing [Internet]. Available from: http://en.wikipedia.org/wiki/3D_ printing [Accessed December 14, 2017]

[16] Lily BC. Taking on the Challenges of Health Care in Africa [Internet]. June 16, 2015. Available from: https://www.gsb.stanford.edu/insights/taking-challenges-health-careafrica [accessed January 21, 2018]

[17] World Health Organization (WTO). The Abuja Declaration: Ten years on [Internet]. Available from: http://www.who.int/healthsystems/publications/Abuja10.pdf [Accessed September 23, 2017]

[18] Eliot N. The Use of Information and Communications Technology (ICTs) in Human Rights Promotion: A Case Study of the African Commission on Human and Peoples' Rights [Thesis]. Msida MSD 2080, Malta: University of Malta; 2015

[19] Helena D. Applications of 3D printing in healthcare. Polish Journal of Thoracic and Cardiovascular Surgery. 2016;13(3):283-293. DOI: 10.5114/kitp.2016.62625 
[20] June J. Dubai Is Going to be Home to the World's First 3D Printed Skyscraper [Internet]. March 16, 2017. Available from: https:/futurism.com/dubai-is-going-to-be-home-to-theworlds-first-3d-printed-skyscraper/ [Accessed January 3, 2018]

[21] Schubert V, Langeveld MCC, Donoso LA. Innovations in 3D printing: A 3D overview from optics to organs. The British Journal of Ophthalmology. 2014;98:159-161. DOI: 10.1136/bjophthalmol-2013-304446

[22] Lu YGT, Wang MY. 3D printing and neurosurgery: Ready for prime time? World Neurosurgery. 2013;80:233-235. DOI: 10.1016/j.wneu.2013.07.009

[23] Permissionless Innovation. Advanced Medical Technology [Internet]. Available from: http://permissionlessinnovation.org/advanced-medical-technology/ [Accessed December 13, 2017]

[24] Banks J. Adding value in additive manufacturing: Researchers in the United Kingdom and Europe look to 3D printing for customization. IEEE Pulse. 2013;4:22-26. DOI: 10.1109/MPUL.2013.2279617

[25] Stratasys. Advancing Health Care with 3D Printing: Applications and guidance on material selection. 2016. pp. 1-34

[26] Alicia M. The Evolution of 3D Printing: Past, Present and Future [Internet]. August 01, 2016. Available from: https://3dprintingindustry.com/news/evolution-3d-printing-pastpresent-future-90605/ [Accessed December 21, 2017]

[27] Sunday AA, Clifford O, Olusina B, Opeyemi F. Barriers to accessing health care in Nigeria: Implications for child survival. Global Health Action. 2014;7:1-10. DOI: 10.3402/ gha.v7.23499

[28] Solomon TA. Access to healthcare facilities: Promises and challenges in Ethiopia [Internet]. The Reporter. November 2013. Available from: http://www.thereporterethiopia.com/ [Accessed July 12, 2017]

[29] Sulaiman P. Africa can improve access to healthcare for all [Internet]. May 08, 2017. Available from: https://www.brandsouthafrica.com/play-your-part-category/play-yourpart-news/other-news/africa-can-improve-access-healthcare+\&cd=5\&hl=en\&ct=clnk [Accessed January 23, 2018]

[30] Council of Europe, European Social Charter (Revised). May 3, 1996. ETS 163

[31] Convention on the Elimination of All Forms of Discrimination against Women. September 1981. General Assembly resolution 34/180

[32] Convention on the Rights of Persons with Disabilities. May 3, 2008. General Assembly resolution $61 / 106$

[33] International Convention on the Elimination of All Forms of Racial Discrimination. January 4, 1969. General Assembly resolution 2106 A (XX) 
[34] Human Rights Watch. Digital Disruption of Human Rights [Internet]. March 25, 2016. Available from: https://www.hrw.org/news/2016/03/25/digital-disruption-human-rights [Accessed December 24, 2017]

[35] Yvonne D. The right to enjoy the benefits of scientific progress: In search of state obligations in relation to health. Medicine, Health Care, and Philosophy. 2011;(4):371-381. DOI: 10.1007/s11019-011-9327-y 
